Corrigendum to

\title{
"Peroxy radical observations over West Africa during AMMA 2006: photochemical activity in the outflow of convective systems" published in Atmos. Chem. Phys., 9, 3681-3695, 2009
}

\author{
M. D. Andrés-Hernández ${ }^{1}$, D. Kartal ${ }^{1}$, L. Reichert ${ }^{1}$, J. P. Burrows ${ }^{1}$, J. Meyer Arnek ${ }^{2}$, M. Lichtenstern ${ }^{3}$, P. Stock ${ }^{3}$, and \\ H. Schlager ${ }^{3}$ \\ ${ }^{1}$ Institute of Environmental Physics, University of Bremen, Germany \\ ${ }^{2}$ German Remote Sensing Data Center (DFD), Oberpfaffenhofen, Germany \\ ${ }^{3}$ Institute of Atmospheric Physics, German Aerospace Center (DLR), Oberpfaffenhofen, Germany
}

Due to an error during the submission of the final figures, the $\mathrm{x}$ axis in Fig. 11 has been wrongly labeled as "latitude" instead of "longitude". The Fig. 11 correctly labeled is shown on the next page. 

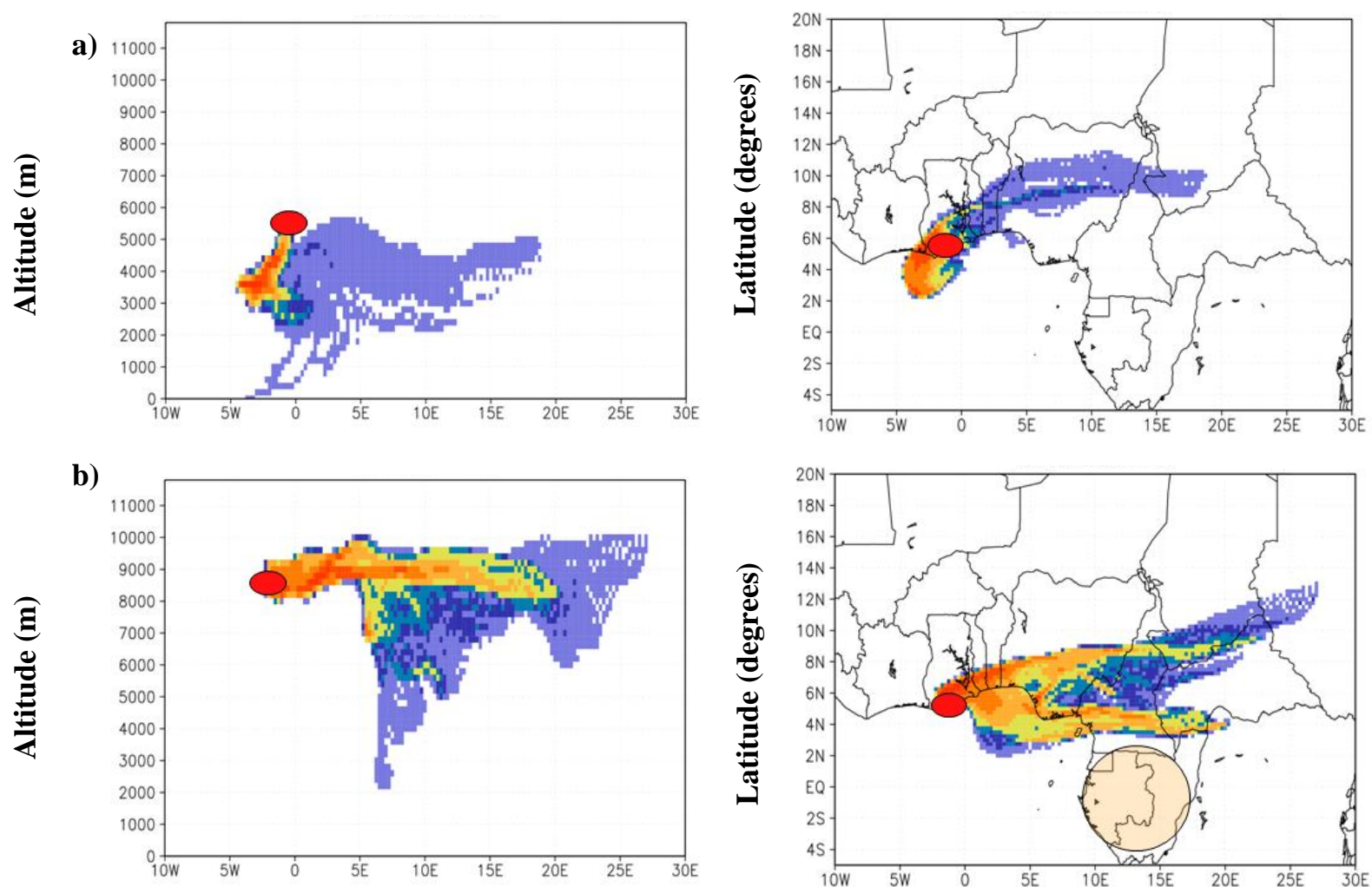

C)
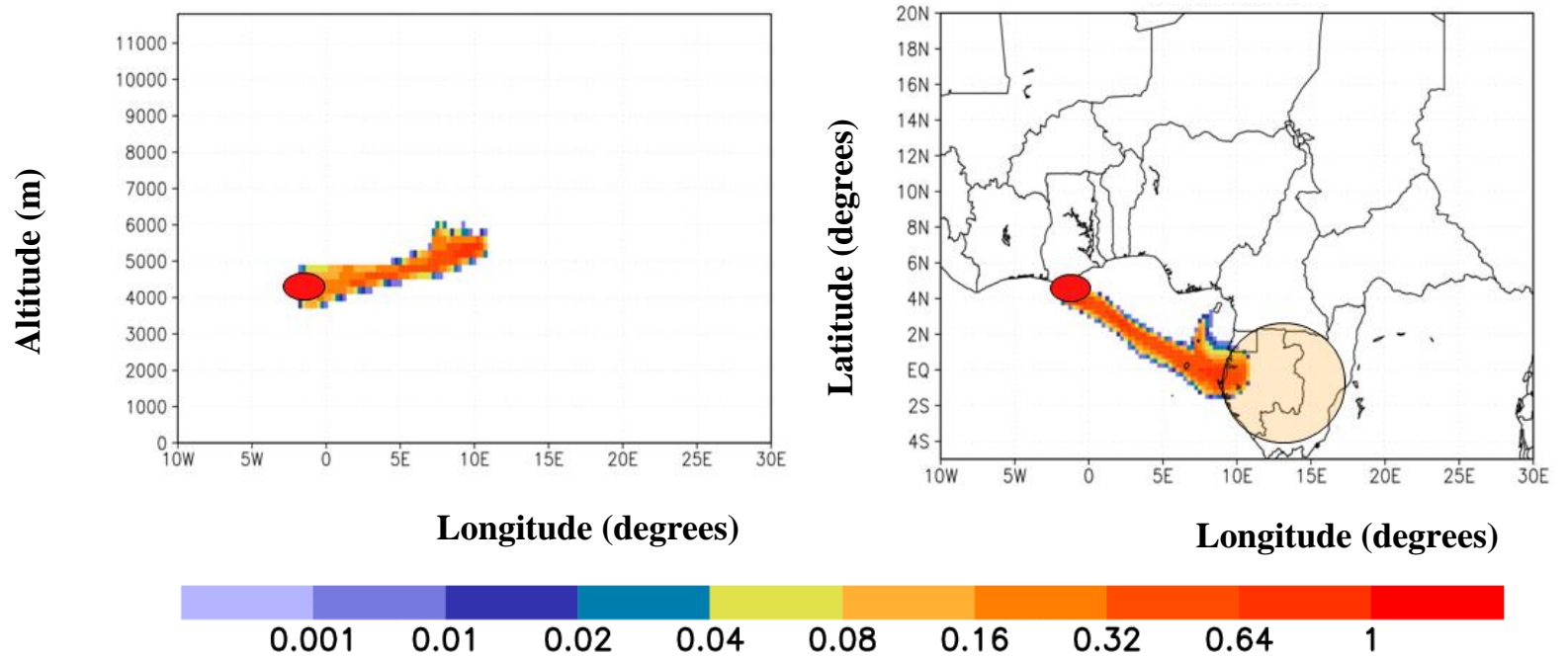

Fig. 11. Trajectory densities calculated for the vertical profile measured on the (a) 4 August 2006 at 10:30 h (b) 13 August 2006 at $11: 40 \mathrm{~h}$ and (c) 13 August 2006 at 12:05 h. The BB area according to satellite data is highlighted. 